\title{
Concussion in youth ice hockey: It's time to break the cycle
}

\author{
L. Syd M. Johnson MA PhD
}

See article by Benson and colleagues on page 905 and at www.cmaj.ca/cgi/doi/10.1503/cmaj.092190 and commentary by Sojka on page 887 and at www.cmaj.ca/cgi/doi/10.1503/cmaj.110504.

$\mathrm{P}$ ittsburgh Penguins captain Sidney Crosby suffered a hard blow to the head in a blind-side collision during the 2011 Winter Classic hockey game. He crashed to the ice, staggered to his feet and slowly left the rink. In a game a few days later, Crosby was slammed against the boards, fell to the ice and exited the game. ${ }^{1} \mathrm{He}$ 's been sidelined indefinitely with a concussion and, according to the concussion protocols of the National Hockey League (NHL), can't return to the game until he's free of symptoms. ${ }^{2}$

Crosby has a lot of company in the NHL, where the number of concussions doubled in the 2010/11 season. ${ }^{3}$ The NHL commissioner attributes the increase in concussions to accidental hits: players being struck by pucks, colliding with teammates, or striking the ice or the boards after being hit legally. ${ }^{3}$ The fact is that the vast majority of concussions, and hockey injuries overall, at all levels of play, are caused by legal bodychecking. ${ }^{4-8}$ It's safe to say that as long as bodychecking is a part of ice hockey, a high rate of concussions will also be a part of hockey. Neither of the blows suspected of causing Crosby's concussion were illegal. That's important - concussion is not a problem the NHL can solve without radically modifying the sport's rules of contact.

\section{Concussion in youth ice hockey}

The NHL's problem with concussions is just the tip of the iceberg; concussion is all too common in youth ice hockey, with evidence that, despite educational efforts, the number of concussions continues to be substantially underreported. ${ }^{4,9,10}$ A study published in late 2010 found an alarming rate of concussions in junior hockey. ${ }^{9}$ In the prospective study, which involved two teams of hockey players aged 1621 years, 17 of 67 players sustained a concussion during a single season, with five of those players also suffering a second concussion. That is, $25.3 \%$ of players sustained at least one concussion in a single season, a rate of concussion seven times higher than the highest rate previously reported in the literature. ${ }^{9}$

An estimated half-million youths play organized minor ice hockey in Canada. ${ }^{11}$ The pediatric population is known to be more vulnerable to concussion and to experience more serious shortand long-term symptoms of concussion than adults. ${ }^{12-15}$ Youth athletes with concussion may experience fatigue, inattention, lack of concentration, memory loss and headaches, which can have devastating effects on both athletic and academic performance. ${ }^{12-16}$ Subtle cognitive deficits may persist for up to a year in some youths. ${ }^{16}$ Youth athletes who sustain minor brain trauma are also at risk for so-called second-impact syndrome, a rare but catastrophic neurologic condition that is almost always fatal. ${ }^{17} \mathrm{~A}$ history of concussion results in substantially increased susceptibility to additional concussions and more severe symptoms of concussion. ${ }^{18}$

Repeat concussions are also a risk factor for chronic traumatic encephalopathy (CTE), which is associated with a spectrum of sequelae including memory loss, behavioural and personality changes, depression, early dementia and motor neuron disease. ${ }^{19}$ In one-half of the confirmed instances of CTE in athletes, symptoms developed within four years of the athletes stopping play. ${ }^{19}$ Subconcussion impacts of the kind common in contact and collision sports, such as hockey and tackle football, are also implicated in CTE. The deposition of tau proteins indica-

\section{- KeY POINTS}

- Concussion is a common, serious injury in youth ice hockey, affecting up to $25 \%$ of players per season by one estimate.

- Bodychecking is a major cause of injury and concussion in hockey, yet some Canadian provinces allow players as young as nine years to engage in bodychecking.

- Reducing rates of concussion requires eliminating bodychecking for all except elite hockey players aged 16 years and older, as per the recommendations of the Canadian Academy of Sports and Exercise Medicine.
Competing interests: None declared.

This article has been peer reviewed.

Correspondence to: syd.johnson@dal.ca

CMAJ 2011. DOI:10.1503 /cmaj.110282 Dr. L. Syd M. Johnson, 
tive of CTE have been found on autopsy in the brains of American football players with no history of concussion, as well as athletes as young as 18 years old. ${ }^{20}$ Concussion causes detectable but subtle symptoms and can be diagnosed by properly trained and vigilant physicians, trainers and coaches, but subconcussion impacts cause silent, invisible, lifelong damage to the brains of youth athletes.

\section{The role of bodychecking}

Bodychecking is a major cause of serious injury, including concussion, in hockey players. ${ }^{4,21,22}$ The American Academy of Pediatrics recommends that bodychecking be prohibited for children younger than 15 years. ${ }^{23}$ Among the reasons cited by the academy is that there can be pronounced variations in body size, physical maturity and strength among players in younger age groups, resulting in heightened risk to smaller players who are matched against much larger players in the same age bracket. ${ }^{23}$

\section{Bodychecking in minor hockey introduces substantial risks of serious injury, including the risk of concussion and lasting brain damage.}

The more conservative recommendation of the Canadian Academy of Sports and Exercise Medicine calls for bodychecking to be eliminated from all levels of minor hockey "which are not designed as training for professional and international ranks," and only beginning in elite Rep or All Star leagues in the 16- to 17-year (Midget level) age group. ${ }^{24}$ Hockey Canada, the governing body of minor hockey, allows bodychecking at the Peewee level (ages 12-13) and above for male players; the Saskatchewan, Ontario and Ottawa hockey leagues permit bodychecking at the Atom level (ages 9-10) on an experimental basis. Quebec permits bodychecking at the Bantam level (ages 14-15). ${ }^{25}$ Quebec is the only province in Canada that has seen growth, rather than decline, in the number of children playing minor hockey, a trend that has been attributed in part to the late introduction of bodychecking. ${ }^{26}$

Hockey Canada's position is that checking skills are critical to the game of hockey and that "players must learn and master all aspects of the checking game to become effective and complete players." ${ }^{25}$ A 2004 study sponsored by the Canadian Hockey Association (now Hockey Canada) concluded that bodychecking "can be taught at the younger age levels in a manner that does not lead to a higher incidence of injuries. ${ }^{\text {"27 }}$ Several studies have confirmed, however, that injury rates rise dramatically when bodychecking is introduced, ${ }^{5-7,7,2,28}$ that players typically sustain their first concussion within a year of starting bodychecking ${ }^{4}$ and that education in "proper" bodychecking technique does not reduce rates of injury. ${ }^{6}$ The evidence strongly suggests that substantial harm may result from teaching youth players bodychecking at an earlier age. ${ }^{5.6,28}$

USA Hockey, the governing body for minor hockey in the United States, permits bodychecking at the Peewee level (ages 11-12), but is currently considering a rule change to raise the age to the Bantam level (ages 13-14), based on a recommendation by the USA Hockey Player Development Sub-committee on Body Checking. ${ }^{29}$ The proposed change is motivated by two factors. First, skill development is hindered when bodychecking is introduced, because players focus on hitting and avoiding being hit rather than on skating, puck- and stick-handling, receiving, shooting and other hockey skills..$^{29}$ The subcommittee argues that players will benefit from two more years of skill development, unhindered by bodychecking. ${ }^{29}$ This is in contrast to Hockey Canada's assertion that training in bodychecking benefits player development. ${ }^{25}$ Second, the US subcommittee cited concerns about player safety, noting a threefold increase in game-related injuries, "including concussion, severe injury and severe concussion," among players aged 11-12 years following the introduction of bodychecking. 8.29

The increased incidence of serious injuries related to bodychecking has also been observed in other countries where bodychecking is not permitted for younger players. ${ }^{7,28}$ In Finland, Mölsä and coauthors observed a disproportionate increase in injuries related to bodychecking, compared with other mechanisms of injury, in the age group for which bodychecking is first introduced. ${ }^{7}$ Additionally, bodychecking was found to be the dominant mechanism of injury in older groups.?

\section{The way forward}

Rates of concussion in hockey are among the highest in all contact sports. ${ }^{4,30}$ There is considerable evidence to support the conclusion that to substantially reduce the number of concussions and subconcussion impacts in junior hockey would require a comprehensive set of changes to how minor hockey is played, including the elimination of bodychecking. ${ }^{5-9,21,24,28}$ The recommen- 
dation of the Canadian Academy of Sport and Exercise Medicine to eliminate bodychecking in all levels of minor hockey except elite leagues, and then only for players aged 16 and older, is a reasonable compromise that acknowledges the need for specialized training for a select few at the elite level of play. ${ }^{24}$ Hockey has a combination of aggressive play, high speed and hard playing surfaces that makes it especially risky for athletes of all ages, and hockey, like most sports, cannot be made $100 \%$ concussion-free. For that reason, better training in detection of concussions and heightened vigilance on the part of coaches, physicians, trainers and parents of hockey players is essential. Also, adherence to return-to-play protocols will always be needed, so that players who do suffer concussions receive proper management and don't return to the ice before they're ready.

More than a decade ago, the NHL led the way in professional sports by adopting postconcussion return-to-play protocols and mandating baseline neuropsychologic testing for its athletes. ${ }^{31}$ The league recently implemented a new protocol for detection of concussions, requiring that players with suspected concussions be examined by a physician for 15 minutes in a quiet off-ice location. ${ }^{32}$

Now, the NHL needs to do more to prevent concussions. But even if nothing changes in professional hockey, more can and should be done to protect junior hockey players. If youth hockey players are not exposed to bodychecking, their chances of experiencing a concussion will decrease considerably. Because the damaging effects of concussion are cumulative, the fewer concussions a youth player has sustained, the better off they'll be in the short and long term. Only 1 in 4000 youth hockey players makes it to the professional league, ${ }^{33}$ but taking measures to limit subconcussion impacts and hits that induce concussion at the junior level, where young athletes often play for more than a decade, means NHL players will have accumulated fewer damaging blows to the head over the entire course of their hockey-playing lives.

Bodychecking in minor hockey introduces substantial risks of serious injury, including the risk of concussion and lasting brain damage. Those risks do not come with comparably important benefits for the $99.9 \%$ of junior hockey players who do not need to develop the skills requisite for playing professional hockey. ${ }^{24,33}$ There is ample evidence to support the conclusion that bodychecking should be banned from all levels of minor hockey, ${ }^{5-7,21,28}$ except leagues where elite players are trained. ${ }^{24}$ Research to determine the optimal age to intro- duce bodychecking, as well as the best practices for teaching bodychecking at elite levels to minimize injury, would be a valuable and needed contribution to the literature on safety in hockey.

The way hockey is played by the professionals is imitated in junior hockey. This creates a vicious cycle in which young athletes learn to play in a way that inevitably causes injury ${ }^{5,21}$ and in turn influence the next generation of players. It's time to break that cycle and teach youths to play in a way that emphasizes skill and protects their brains, so they'll be prepared to do the same when they grow up. There are a lot of kids who want to be the next Sidney Crosby, but they ought to be able to play the sport they love without being the next hockey player with a concussion.

\section{References}

1. Gulli C. The damage done. Maclean's 2011 Feb. 4: 50-4.

2. Rosen D. How can a concussed player get back on the ice? NHL.com; 2010 Mar. 12. Available: www.nhl.com/ice/news .htm?id=545327\#\&navid=nhl-search (accessed 2011 Mar. 21).

3. Associated Press. NHL concussions on rise, accidental hit blamed. NHL.com; 2011 Jan. 29. Available: www.nhl.com/ice /news.htm?id=551016 (accessed 2011 Apr. 4).

4. Goodman D, Gaetz M, Meichenbaum D. Concussions in hockey: There is cause for concern. Med Sci Sports Exerc 2001;33:2004-9.

5. Macpherson A, Rothman L, Howard A. Body-checking rules and childhood injuries in ice hockey. Pediatrics 2006;117:e143-7.

6. Hagel BE, Marko J, Dryden D, et al. Effect of bodychecking on injury rates among minor ice hockey players. CMAJ 2006; 175:155-60.

7. Mölsä J, Kujala U, Myllynen P, et al. Injuries to the upper extremity in ice hockey: analysis of a series of 760 injuries. Am J Sports Med 2003;31:751-7.

8. Emery CA, Kang J, Shrier I, et al. Risk of injury associated with body checking among youth ice hockey players. JAMA 2010; 303:2265-72.

9. Echlin PS, Tator $\mathrm{CH}$, Cusimano MD, et al. A prospective study of physician-observed concussion during junior ice hockey: implications for incidence rates. Neurosurg Focus 2010;29:E4.

10. Williamson IJS, Goodman D. Converging evidence for the under-reporting of concussion in youth ice hockey. Br J Sports Med 2006;40:128-32.

11. Hicks B. Hard times ahead for national sport. CBC.ca; 2009 Jan. 12. Available: www.cbc.ca/sports/hockey/ourgame/story/2009 /01/05/registration-part1.html (accessed 2011 Mar. 21).

12. Grady MF. Concussion in the adolescent athlete. Curr Probl Pediatr Adolesc Health Care 2010;40:154-69.

13. Purcell L, Carson J. Sport-related concussion in pediatric athletes. Clin Pediatr (Phila) 2008;47:106-13.

14. Moser RS, Schatz P, Jordan BD. Prolonged effects of concussion in high school athletes. Neurosurgery 2005;57:300-6.

15. McCrory P, Collie A, Anderson V, et al. Can we manage sport related concussion in children the same as in adults? Br J Sports Med 2004;38:516-9.

16. Boutin D, Lassonde M, Robert M, et al. Neurophysiological assessment prior to and following sports-related concussion during childhood: a case study. Neurocase 2008;14:239-48.

17. Bey T, Ostick B. Second impact syndrome. West J Emerg Med 2009;10:6-10.

18. Collins MW, Lovell MR, Iverson GL, et al. Cumulative effects of concussion in high school athletes. Neurosurgery 2002;51: 1175-79.

19. McKee AC, Cantu RC, Nowinski CJ, et al. Chronic traumatic encephalopathy in athletes: progressive tauopathy following repetitive head injury. J Neuropathol Exp Neurol 2009;68:709-35.

20. Center for the Study of Traumatic Encephalopathy - Boston University. 18 year old high school football player. Boston (MA): The Center; 2009. Available: www.bu.edu/cste/case -studies/18-year-old/ (accessed 2011 Feb. 8).

21. Cusimano MD, Taback NA, McFaull SR, et al. Effect of bodychecking on rate of injuries among minor hockey players. Open Med 2011;5:E57-64 
22. Marchie A, Cusimano MD. Bodychecking and concussion in ice hockey: Should our youth pay the price? CMAJ 2003;169:124-8.

23. Safety in youth ice hockey: the effects of body checking. American Academy of Pediatrics Committee on Sports Medicine and Fitness. Pediatrics 2000;105:657-8.

24. Kissick J. Canadian Academy of Sport and Exercise Medicine Position Statement: violence and injuries in ice hockey. Ottawa (ON): Canadian Academy of Sport and Exercise Medicine; 2007. Available: http://casem-acmse.org/pg_Statements.php (accessed 2011 Feb. 14)

25. Background on checking. HockeyCanada.ca; 2011. Available: www.hockeycanada.ca/index.php/ci_id/6862/la_id/1/ss_id/6887. htm (accessed 2011 Mar. 21).

26. Rutherford K. Quebec hockey bucking the trend: initiation hockey is surging while other provinces struggle to maintain current numbers. CBC.ca; 2009 Jan. 20. Available: www.cbc.ca /sports/hockey/ourgame/story/2009/01/12/registration-quebec.html (accessed 2011 Mar. 21).

27. Montelpare WJ, McPherson MN. Measuring the effects of initiating body checking at the Atom age level. In: Pearsall DJ, Ashare AB, editors. Safety in ice hockey: fourth volume, ASTM STP 1446. West Conshocken (PA): ASTM International; 2004 p. $70-84$.

28. Warsh JM, Constantin SA, Howard A, et al. A systematic review of the association between body checking and injury in youth ice hockey. Clin J Sport Med 2009;19:134-44.
29. Hockey USA. Bodychecking rule proposal. USA Hockey Available: www.usahockey.com//Template_Usahockey.aspx?NAV =ET 03\&ID=299508 (accessed 2011 Mar. 22).

30. Koh JO, Cassidy JD, Watkinson EJ. Incidence of concussion in contact sports: a systematic review of the evidence. Brain Inj 2003; 17:901-17.

31. Lovell MR. The relevance of neuropsychological testing for sports-related head injuries. Curr Sports Med Rep 2002;1:7-11.

32. Rosen D. New concussion protocol goes into effect tonight. NHL.com; 2011 Mar. 16. Available: www.nhl.com/ice/news .htm?id=556289\#\&navid=nhl-search (accessed 2011 Mar. 21).

33. Kalchman L. Making NHL a very long shot. HockeyCanada.ca; 2003 Jan. 25. Available: www.hockeycanada.com/index.php /ci_id/10767/la_id/1/ (accessed 2011 Feb. 14).

Affiliation: From Novel Tech Ethics, Dalhousie University, Halifax, NS

Funding: Research funded by Canadian Institutes of Health Research, MOP 77670, Therapeutic Hopes and Ethical Concerns: Clinical research in the neurosciences, and NNF 80045, States of Mind: Emerging issues in neuroethics.

Acknowledgements: The author thanks anonymous reviewers who provided valuable and informative feedback on this paper. 